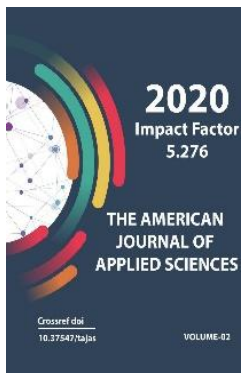

\title{
The Course Of Pathological Anatomy In A Modular System, As A New Teaching Technology In A Medical University
}

\section{Zhuraeva Gulbahor Bakhshillaevna}

Bukhara State Medical Institute Named After Abu Ali Ibn Sina, Uzbekistan

Copyright: Original content from this work may be used under the terms of the creative commons attributes 4.0 licence.

\section{ABSTRACT}

This technology of learning makes the student learn not just to cram the textbooks and reference books, but also to understand independently the information sought, to find the necessary knowledge. At the same time, he has a feeling of satisfaction from the work done, and the knowledge that he has gained is firmly deposited in his memory. At the end of the time allotted for the study of the module, it is necessary to check the received knowledge, their completeness and compliance with the task.

\section{KEYWORDS}

Modular training, modular program, medicine, form of classes.

\section{INTRODUCTION}

Modular teaching in higher education has proven its strength, relevance and success for many years. It avoids many problems of presentation and study of material in all disciplines. It began as an alternative to traditional teaching in the 6os in the UK, USA, and Canada. Later, this approach attracted the attention of scientists from all over the world and took a worthy place in the "pedagogical poverty" assigned to it. 
Based on the analysis of the activities of an employee in the field of medicine, in particular, doctors with experience that successfully solves scientific and practical problems. Thanks to the correct concept and a high degree of perception of the objective logic of organizations and behavioral changes in a person, in this case they accept the human body as an integral open system. Traditionally, the presentation of the high school course in pathological anatomy is informational in nature, offers a huge amount of new information, the assimilation of which is difficult due to the peculiarities of the training in medical universities. The use of modular technology allows you to develop independence, plan and control the mastery of the subject, and make self-assessment. A module is a target functional unit that combines educational content and technology for mastering it into a system of a high level of integrity. The main functions of problemmodular training, the development of practice-oriented potencies, the development of skills for the creative assimilation of knowledge, the ability to independently solve professional, organizational, scientific and other problems, as well as the formation of motivation for learning, scientific and cognitive needs and interest in future professional activities. When studying a subject for medicine, this method should give more information than traditional methods. Moreover, on this plan, the structure of the module, which includes goals and objectives, educational elements, generalizations and control, is of fundamental importance. The development of modern medicine in teaching a profession offers a high level of independence with the leading role of the student's personality, the provision of a wide range of educational services by a vocational education institution, variability methods of knowledge control.

Reorganization of the learning process according to modular programs allows:
1. To integrate and differentiate the content of training by grouping problem modules, training material, abbreviated and indepth versions.

2. To carry out an independent choice of methods and forms of teaching: the active use of modern pedagogical technologies for students of one or another option in the course of pathological anatomy in a complete, abbreviated form.

3. To emphasize the work of the teacher on the consultative and coordinating functions of managing the cognitive activity of students.

4. To shorten the course of study without special prejudice to the completeness of presentation and the depth of assimilation of educational material on the basis of an adequate set of methods and forms of training.

5. A large volume of work is carried out by the student independently. If necessary, the task is repeated through the training element.

The fundamental stage in the design of modular learning technology is the development of modules. Let's consider this on the example of a block structure: 


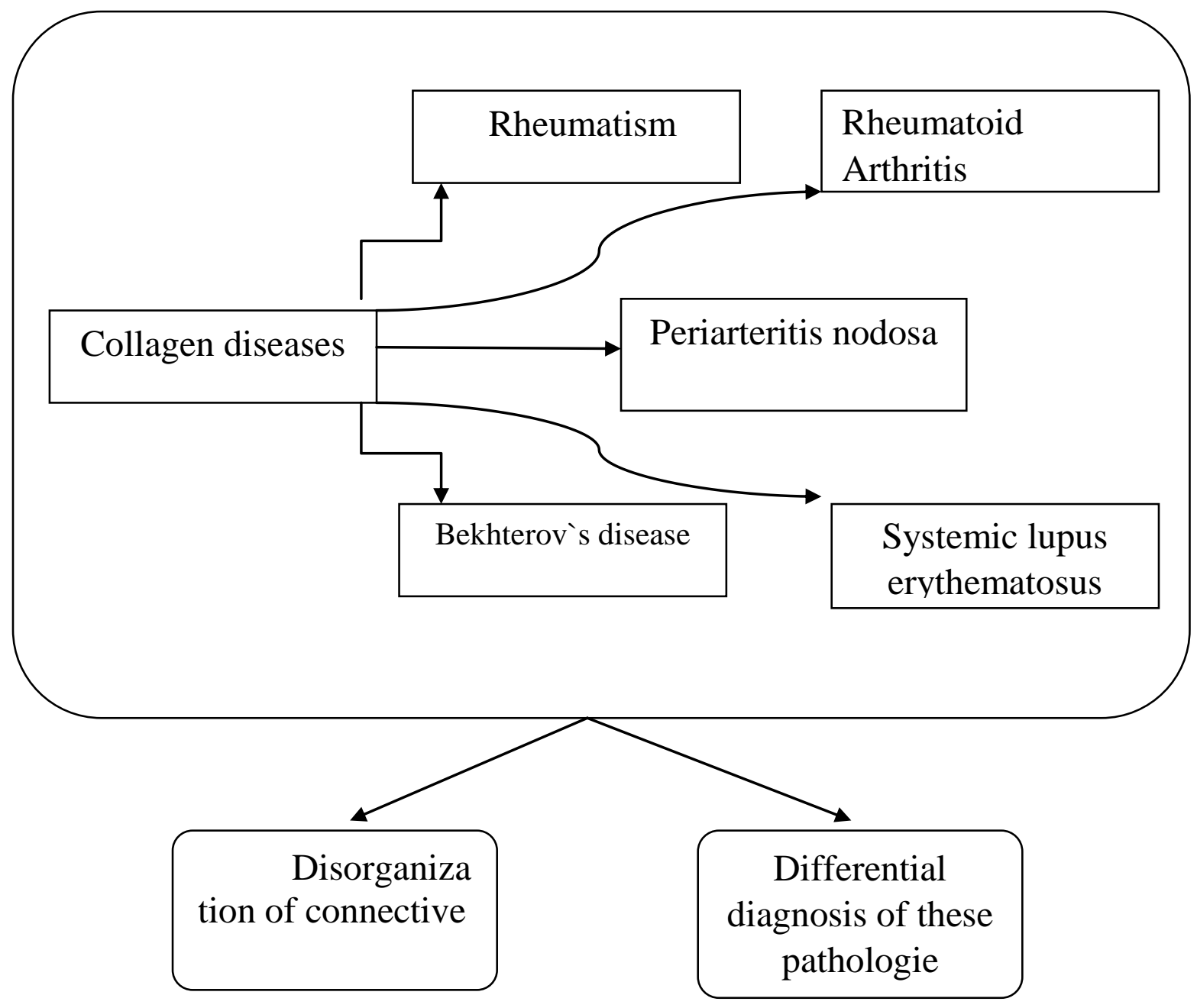

In this example, each built block of a module can be logically connected, visually connected with the previous one, forming new uniform blocks, the application of the material, it is lined up into a single block (the principle of block structure). There are important connections between these blocks; each disease is also studied in certain modules. This is just one example of the implementation of the principles of modular training by which one can easily judge their importance and application at all stages of the study of pathological anatomy at a university.

The role of the teacher-consultant in modular training encourages the student to cooperate, this is expressed in preparation for the basic lessons of in-depth study, as well as in reporting on the topics covered in the module.

Point - the rating assessment of knowledge provides for a variety of control (attendance, classroom and extracurricular work, 
completing additional tasks and control tests, solving situational tasks) as well as the application of criteria for evaluating the work performed, monitoring the deadlines, expressed in points. However, unlike the topic in the module, everything is measured, everything is assessed: assignment, work, attendance at classes, and starting, intermediate and final level of students. The module clearly defines the learning objectives, tasks and levels of study of this module, the skills and abilities are named. In modular training, everything is pre-programmed: not only the sequence of studying the educational material, but also the level of its assimilation and control of the assimilation quality.

Our modular program (modules) is a bank of information, which was developed by the team of the department. Modular training programs are formed as a set of modules. When determining the overall grade for the course, the results of the rating are included in it with the appropriate weighting coefficients established by the authors-teachers of the course. Students know a list of basic concepts, skills and abilities for each specific module, including a quantitative measure for assessing the quality of mastering educational material. Based on this list, questions and educational tasks were compiled, covering all types of work in the module, and submitted for control after studying the module. As a form of control, we use test control.

In modular training, each task is evaluated in points, its rating and deadlines are set (the corresponding number of points also evaluates timely completion of the task), i.e. the main principle of rating control is control and assessment of the quality of knowledge and skills, taking into account the systematic nature of students' work.

The modular learning technology is because the student must independently study the selected part of the course according to an individual scheme. The teacher gives the student a so-called training module, which consists of a complete block of information, an action program, the purpose of which is to study this information in the most complete way, recommendations for the successful achievement of the goal and solving the tasks set in the module.

The learning process becomes as independent as possible, however, it is recommended to consult with the teacher on issues that arise during the course of the module. Such a teaching technology forces the student to learn not just to cram textbooks and reference books, but to independently understand the required information, find the necessary knowledge. At the same time, he has a feeling of satisfaction from the work done, and the knowledge gained firmly settles in his memory. At the end of the period allotted for the study of the module, the knowledge gained, its completeness and compliance with the task are checked.

Thus, the essence of modular learning is that the student independently or with a certain dose of help achieves specific learning goals in the process of working with the module and creates conditions for independent cognitive creative activity, ensuring the development and personal growth of students, i.e. control is considered as an integral part of the educational process.

\section{REFERENCES}

1. Akimova I.V, Gubanova O.M, Titova EI Possibilities of implementing a modular approach in teaching bachelors of pedagogical specialties on the example of the topic "Introduction to logic algebra" Modern problems of science and education-2013.-№5.- S-230. 
2. Aimagambetov M.M. Training on a modular system // Professional of Kazakhstan.-2006.-№7.-C. 10-11.

3. Blokhin N.V. The technology of modular open learning in the system of modernization of education / N.B. Blokhin // Psychological support of the processes of modernization of education and professionalization of personnel: Materials of the international symposium. Part 1.-2020.-C24-25.

4. 4..Burkina V.A., Titova E.I. On some of the priorities of modular training at the University "Young Scientist". - 2014-№4-C 925-927.

5. Ciavichene P. Yu. Theory and practice of modular training / P. Yu. Ciavichene // Sov. Pedagogy. - 2009. - No. 1. - P. 55-60.

6. Garayev V. M. Principles of modular training / V. M. Garayev, S. I. Kulikov, E. M. Durko // Bulletin of the higher school. 2008. - No. 8. - P. 30-33. 6.

7. Goloshchekina LP, Zbarovskiy B. C. Modular teaching technology: Methodical recommendations. - SPb .: UNITY-DANA, 1993.3.

8. Koroleva, VV Modular training as one of the ways to improve the quality of specialist training / VV Koroleva. - Text: direct // Young scientist. - 2015. - No. 3 (83). - S. 787-790.

9. Lopanova E.V. Development of a training program for teachers of a medical university based on a competency-based approach // Medical education and professional development.-2012; 1: 132135.

10. Lavrentyeva N.B. Pedagogical foundations of the development of modular learning technology. Yekateringburg, 1994.-88p.

11. Mazhenova G.A., Muratbekova G.A., Pyagay N.P. "Medicine and Ecology" A modular training program in the preparation of mid-level medical workers. -2007.-№7-C 47-50.

12. Potashnik M.M., Levit M.V. How to prepare and conduct a lesson (modern technology) -SPb 2011 8. M.: Pedagogical Society of Russia.

13. Petrov L.I., Kuterkigina L.N. Methodological support of the Bologna process in the university.-Rostov $\mathrm{n} / \mathrm{a}$. 2008-656 p.

14. Shapalova V.A. Modular training in a medical university "Education: problems and solutions" -2015.-№ 7-C 53-54.

15. Trainev I.V. Constructive pedagogy.-M., 2004.-320.

16. Tretyakov PI, Sennovsky IB Technology of modular education in school: Practiceoriented monograph / ed. P.I. Tretyakov. M .: New school, 1997.

17. Vasilyeva IN Interactive learning and modular pedagogical technologies / IN Vasilieva, OA Chepenko // Specialist. 2010. - No. 6.- P. 18-22. five. 